\title{
Chapter 4 \\ Role of the Microbial Burden \\ in the Acquisition and Control of Healthcare \\ Associated Infections: The Utility of Solid \\ Copper Surfaces
}

\author{
Michael G. Schmidt, Andrea L. Banks, and Cassandra D. Salgado
}

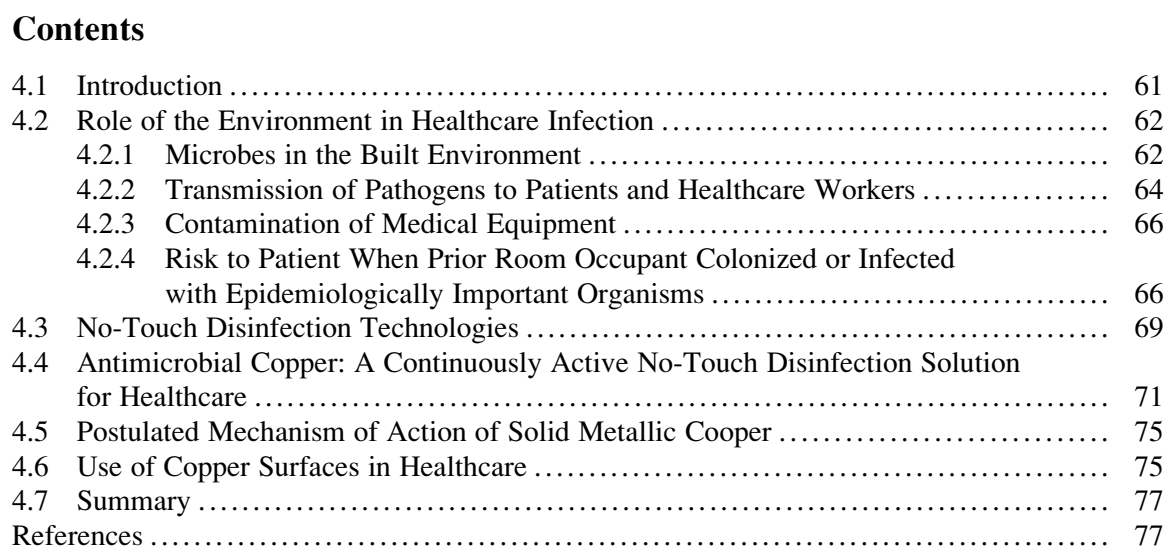

\begin{abstract}
For more than a century, healthcare has been challenged to keep environmental surfaces clean to control microbes and improve patient outcomes. However despite an annual cost exceeding ten billion dollars cleaning with disinfection has done little to reduce the incidence of healthcare-associated infections (HAI). This chapter will review the scientific evidence delineating the role that the environment and healthcare workers play in the acquisition and movement of
\end{abstract}

\footnotetext{
M.G. Schmidt, Ph.D (ه)

Department of Microbiology and Immunology, Medical University of South Carolina, 173 Ashley Ave-MSC•504, BSB 214A, Charleston, SC 29425, USA

e-mail: schmidtm@musc.edu
}

\begin{abstract}
A.L. Banks, M.D. • C.D. Salgado, M.D. M.S.
Department of Medicine, Division of Infectious Diseases, Medical University of South Carolina, 135 Rutledge Tower- MSC • 752, Charleston, SC 29425, USA

e-mail: banksa@musc.edu; salgado@musc.edu
\end{abstract}


the microbes implicated in HAI and how through controlling the microbial burden of the built clinical environment it is possible to mitigate the rate of HAI acquisition. Specifically evidence demonstrating the effectiveness of solid copper surfaces for its ability to continuously limit the concentration of bacteria found on surfaces and objects within the built environment will be reviewed in concert with a discussion of how through the mitigation of the environmental burden copper surfaces are able to concomitantly reduce the incidence of HAI. Insights provided by this chapter are intended to facilitate an understanding and importance of the need to use a comprehensive or systems based approach to fight healthcare associated infections.

Keywords Hospital Associated Infections (HAI) • Antimicrobial Copper

\section{List of Abbreviations}

CA-ASB Catheter associated bacteriuria

CAUTI Catheter-associated urinary tract infections

CFU Colony-forming units

CI Confidence interval

CLABSI Central line-associated bloodstream infections

CDI Clostridium difficile infection

EPA Environmental Protection Agency

HAI Hospital associated infections

HCWs healthcare workers

HPV Hydrogen peroxide

HTOs High touch objects

ICU Intensive care unit

IDSA Infectious Disease Society of America

IV Intravenous

KPC Klebsiella pneumoniae carbapenemase

MRSA Methicillin resistant Staphylococcus aureus

MDR Multi-drug resistant bacteria

PFGE Pulsed field gel electrophoresis

PMF Proton motive force

PPE Personal protective equipment

OR Odds ratio

SSI Surgical site infections

UTI Urinary tract infections

UV Ultraviolet

VAP Ventilator-associated pneumonia

VRE Vancomycin resistant enterococci 


\subsection{Introduction}

Hospital associated infections (HAI) continue to be a common and significant complication of hospitalization, leading to increased morbidity and mortality. It was estimated that in 2002, there were approximately 1.7 million healthcareassociated infections, which resulted in approximately 99,000 deaths [41]. A more recent meta-analysis of the costs and financial impact of HAI on the US healthcare system reported that the total annual costs for the five major infections (central line-associated bloodstream infections (CLABSI), ventilator-associated pneumonia (VAP), surgical site infections (SSI), Clostridium difficile infection (CDI), and catheter-associated urinary tract infections (CAUTI)) were $\$ 9.8$ billion (95\% confidence interval (CI) $\$ 8.3$ to $\$ 11.5$ billion) [106]. There has been an unprecedented movement for healthcare facilities to improve patient safety and certainly prevention of HAI represents a major portion of that effort.

The process by which a patient acquires an infection while hospitalized is complex. This has been elegantly illustrated and described by Dr. Weinstein (Fig. 4.1), highlighting the role of the patient's endogenous flora, exposure to exogenous flora, as well as the influence of devices and pressure from antibiotic use [101]. Recent development and implementation of strategies to prevent HAI have included such efforts as antimicrobial stewardship, interrupting transmission of epidemiologically important organisms, and infection specific prevention bundles; however, there is renewed interest in defining the role of environmental contamination in transmission of nosocomial pathogens and development of HAI.

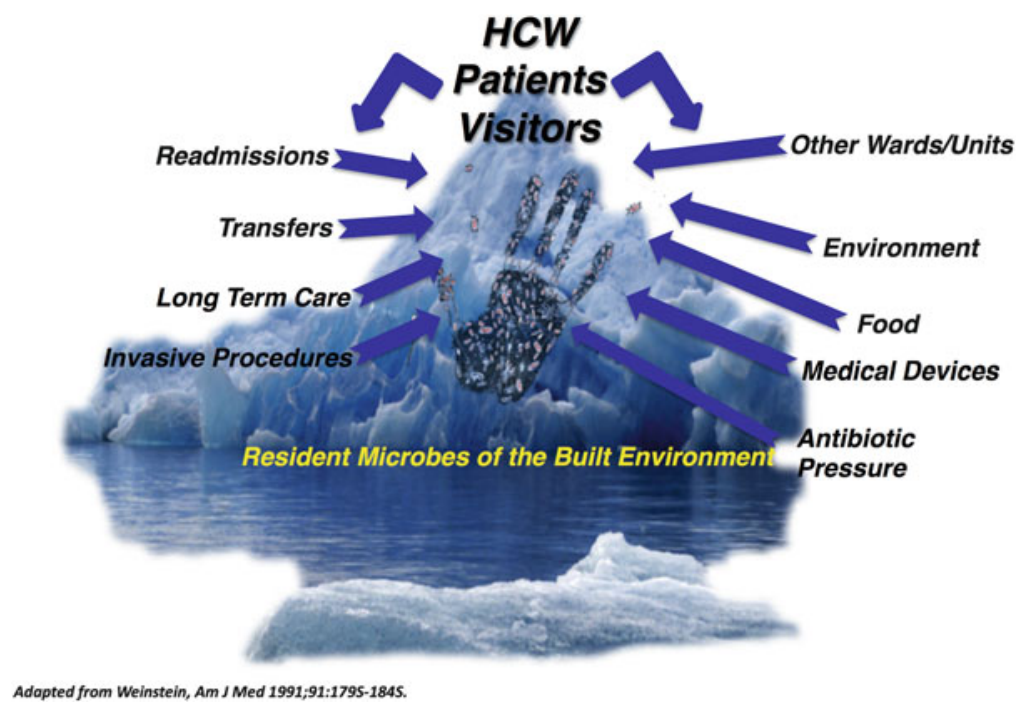

Fig. 4.1 Hazards in the hospital (Adapted from the figure by Weinstein [101]). The complexity and dynamic nature of the microbial pressure being introduced into the built clinical environment is dependent on stochastic nature inherent to healthcare 
The purpose of this chapter is to review the role of the environment of care as it pertains to microbial contamination and risk of HAI to patients as well as describe the novel use and efficacy of antimicrobial copper surfaces in mitigating this risk. We will discuss problematic pathogens in healthcare, their ability to contaminate and persist in the environment, their ability to contaminate the healthcare provider, and ultimately their ability to directly or indirectly result in colonization and infection in the patient. We will briefly review the traditional measures utilized to reduce the microbial burden associated with the healthcare environment but focus our discussion on the use of continuously active antimicrobial solid copper for this purpose. Given that, we describe the proposed mechanism of action for copper's antimicrobial property, its activity against pathogens commonly found in healthcare, as well as the clinical efficacy of placing solid copper surfaces into the patient care environment.

\subsection{Role of the Environment in Healthcare Infection}

The majority of healthcare associated infections are thought to occur via transmission from the patient's own endogenous flora. However, there is increasing evidence that there exists significant transmission of microbes from healthcare personnel and the hospital environment to vulnerable patients. A study published in 1991 estimated that the causative source of an HAI in the Intensive Care Unit (ICU) was the patients' endogenous flora 40-60\% of the time and antibiotic driven changes in flora $20-25 \%$ of the time. Cross-infection via the hands of personnel accounted for $20-40 \%$ of cases and other sources, including contamination from the environment, accounted for the remaining $20 \%$ [101]. It has been established that the inanimate hospital environment can become contaminated with nosocomial pathogens after exposure to colonized patients [36]. This environment includes surfaces within the hospital room (bedrails, bedside tables, etc.) and medical equipment. A review of the available literature in 2002 concluded that personal and environmental hygiene reduced the spread of infections [1]. More recent literature has provided additional evidence that contaminated hospital surfaces are a source of transmission of nosocomial pathogens [57]. Otter and colleagues delineated the continuous, omni-directional and complex nature of how microbes can easily move between infected or colonized patients, healthcare workers, and objects resident in the built environment (Chap. 3 and ref [57]) (Fig. 4.2).

\subsubsection{Microbes in the Built Environment}

Microbes have an innate ability to contaminate and potentially establish residence on any surface. Surfaces with frequent hand contact and in close proximity to the patient are often colonized with nosocomial pathogens, and most of these pathogens can 


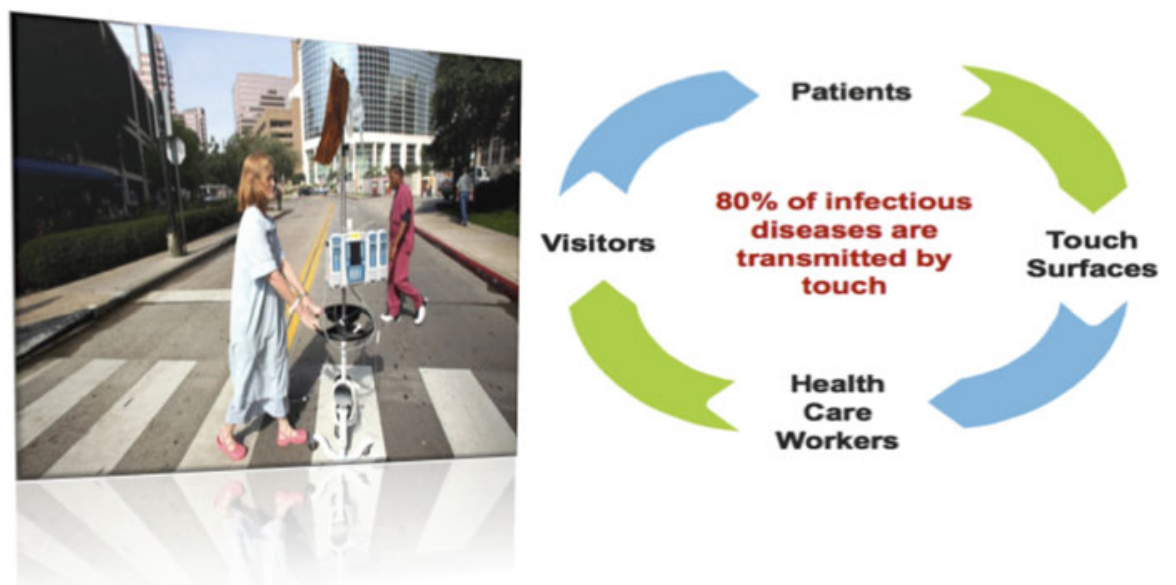

Fig. 4.2 Transmission dynamic of microbes resident in the clinical environment. the ubiquitous distribution of microbes, coupled with the stochastic nature of care, facilitates a continuous risk of the patient, healthcare worker or high touch object introducing, acquiring or spreading unwanted microorganisms

remain viable on these inanimate surfaces for weeks to months (Chap. 2 and ref [42]). Further, the distribution and dispersal of the microbes from healthcare workers, visitors and patients can contribute to the resident microbial flora of the built environment. Humans shed a minimum of ten million of their 100 million skin cells per day. Routine activities such as walking can result in the loss of approximately $10^{4}$ skin particles per minute with a complete layer of skin cells being lost and replaced from healthy individuals on average approximately every 4 days [51]. The displaced skin cells are covered with the endogenous flora of the individual. Not all individuals shed skin equally. In one study of microbial dispersal by skin in a hospital ward, Noble defined a 'Staph aureus disperser' as a patient who contributed greater than six S. aureus per cubic meter of air [52]. Given that the mean concentration of bacteria within the ward was the equivalent of 800 viable bacteria per cubic meter, the concentration of S. aureus observed was thought to represent $1 \%$ of the total flora [52]. Over the years the number has been revised to suggest that an individual is a 'Staph aureus disperser' when they are able to disseminate more than four viable particles per microbe per cubic meter of air [9]. Causality, or the linkage of an environmental isolate to that organism responsible for disease in individuals has been demonstrated as early as 1945 when deForest and Kerr reported cases of eczema which occurred amongst nurses that were caused by streptococci that were shed [26]. With the advent of molecular techniques, such as Pulsed Field Gel Electrophoresis (PFGE) and whole genome sequencing, the ability to demonstrate casualty has now become much more straightforward but is still nevertheless time intensive and cost prohibitive.

Once established within the built environment the microbe must then be able to resist the perturbations introduced as a consequence of cleaning and other infection control measures. To that end, some pathogens have become resistant to 
disinfectants used on environmental surfaces, thus leading to their persistence and continued distribution within the built environment and presenting a continued risk of being transferred to a patient, healthcare worker or object within the built hospital environment [100].

\subsubsection{Transmission of Pathogens to Patients and Healthcare Workers}

Certain factors must be met for a microbe to transition from its role as an inhabitant of the surfaces associated with the built clinical environment to pathogen that can be transmitted to a patient or healthcare worker. First, the pathogen must be able to survive on the objects and surfaces within the environment for a sufficiently long period of time while retaining its ability to be virulent or its ability to colonize a susceptible host after its subsequent liberation from the surface and resulting transmission/establishment. Second, contamination of the environment by a particular pathogen must be sufficiently frequent to account for its loss from the object or surfaces as a consequence of routine cleaning, desiccation, or starvation. Third, the agent must be present at a concentration sufficient to establish itself upon encountering the new host or location. Certain nosocomial pathogens, such as Norovirus, have incredibly small infectious doses with a median dose of 18 viruses [86] while the environmental dose of the causative agent of the majority of CAUTI, Escherichia coli, is not as evident. The Infectious Disease Society of America (IDSA) has classified that in the absence of symptoms a concentration of $\geq 10^{5}$ colony forming units (CFU) per ml coupled where $\geq 1$ bacterial species is present in the urine of a catheterized patient that the individual has an asymptomatic catheter associated bacteriuria (CA-ASB) [35]. A CAUTI is defined as the "presence of symptoms or signs compatible with urinary tract infections (UTI) with no other identified source of infection along with $\geq 10^{3} \mathrm{CFU} / \mathrm{mL}$ of $\geq 1$ bacterial species" from a catheterized or previously catheterized $(\leq 48 \mathrm{~h}$ ) urine sample [35]. However the guidelines are silent as to the origin and/or concentration of the microbe(s) required to establish the CA-ASB or CAUTI. The concept of infectious dose from the environment as it pertains to nosocomial infection has not been rigorously studied for the majority of the HAI. Further study is warranted.

Hospitals have put into place measures in an attempt to decrease the contamination or likelihood of colonization of healthcare workers with infectious pathogens. Focus has been placed on increased hand hygiene, contact precautions, and enhanced environmental cleaning. In 2006 Pittet and colleagues presented an evidence-based model arguing for improved hand hygiene practices during patient care as being the most important method for preventing HAI and spread of antimicrobial resistant pathogens [61]. In their model, five steps are required for the transmission of pathogens within the clinical care setting. Collectively, the model considers the microbes and their transmission from objects, healthcare workers, and patients to the next individual or object. The first step requires that the microbe be present or resident 
on the patients'/healthcare workers' skin or immediate environment. The concentration of the nosocomial pathogen can vary from as few as 1 to over $10^{6} \mathrm{CFU}$ per $\mathrm{cm}^{2}$. Subsequently, the microbe must be transferred to the healthcare worker. Simple acts such as lifting a patient, obtaining a blood pressure, pulse, or assessing a temperature can easily result in the transfer of between 100 and 1,000 CFU of a common Gramnegative pathogen Klebsiella spp. [19]. In fact these authors learned that $17 \%$ of the staff of an intensive care unit were found to have Klebsiella contaminating their hands when screened and that the serotypes were related to those isolated from infected or colonized patients within the ICU on the same day [19]. Further advancing the importance of hand hygiene was a study that found healthcare workers were as likely to contaminate their hands or gloves from commonly-touched environmental surfaces as from direct contact with colonized patients [85].

The third aspect of the model is dependent upon the biology of the microbe. Some microbes can survive for longer periods of time on hands than others. Epidemic and non-epidemic strains of E. coli and Klebsiella spp. were found to have significantly different survival times [30] supporting the argument that bacterial properties other than the survival of a typed strain under defined conditions may contribute to the ability of a microbe to be easily transmitted and retained within healthcare setting. In other studies workers found that bacterial colonization of the hands of healthcare workers progressively increased with time [60, 62]. In these two studies they found that the concentration of commensal and pathogenic flora increased as a consequence of patient care. Additionally, the authors reported that the dynamics of hand contamination were independent of whether or not the healthcare worker was working while gloved or ungloved [60, 62].

Such an establishment of causality in the development of HAI, and an intrinsic ability to survive on the hands of the healthcare workers, provides strong support for a role for hand hygiene for limiting the incidence and controlling the spread of HAI. The fourth and fifth aspects of the model advanced by Pittet and colleagues addresses the issue of defective and/or absent hand cleansing and how it can lead to the cross transmission of the microbes [61]. Here they have raised the issue of the need to microbiologically validate proper hand cleansing in order to control the spread of microbes regardless of their source. In citing a study by Sala and colleagues, they describe how an outbreak of Norovirus was traced to an infected food handler within a hospital cafeteria. Here the implicated foodstuffs consumed during the outbreak were handmade by the infected worker [69]. Independently, it has been shown that Norovirus contaminated fingers can sequentially transfer this virus to up to seven surfaces [7]. Sequential transfer is not only confined to human to surface transfer. In the same study, the virus was found to move from contaminated cleaning cloths to clean hands and surfaces [7]. Recently, Snitkin and colleagues used whole genome sequencing to track an outbreak of Carbapenem-Resistant Klebsiella pneumonia that occurred at the U.S. National Institutes of Health Clinical Center where they learned that despite early implementation of infection control procedures, including aggressive hand hygiene controls, the microbe persisted in the environment [83]. Consequently, the built environment can serve as a reservoir from which clean hands can serve as a source of HAI. 


\subsubsection{Contamination of Medical Equipment}

When a patient is known to be colonized or infected with a transmittable pathogen, dedicated equipment (i.e. stethoscopes) should be used when possible along with other personal protective equipment such as gowns, gloves and masks. Frequently touched hospital surfaces and medical equipment, such as doorknobs, bed rails, faucet handles, and intravenous (IV) poles, have been identified as reservoirs of pathogenic microbes $[10,56]$. In addition to medical equipment and healthy or intact skin, there have been reports of the transfer of bacteria to the gloves and gowns of healthcare workers after patient contact [6, 18, 33, 49]. Specifically, Morgan and colleagues reported that the transfer of multi-drug resistant bacteria (MDR) to the gowns and gloves of healthcare workers occurred after routine contact, and that this was found to increase as environmental contamination increased [49]. The intent of the study was to evaluate the differential rate of contamination by a MDR variant of Acinetobacter baumannii compared with other MDR bacteria while attempting to understand the importance of environmental contamination in the transfer of MDR bacteria to personal protective equipment (PPE, (gowns and gloves)) of healthcare workers. Here the microbe most frequently recovered was the extremely recalcitrant multidrug resistant variant of A. baumannii. Most striking however, were the conclusions that resulted from the modeling of their data. Here a positive environmental culture was found to be the strongest risk factor associated with the contamination of the clothing of the healthcare worker by MDR bacteria (Odds ratio (OR) 4.2; $95 \%$ CI 2.7-6.5) [49]. Other independent variables, such as presence in the patient's room for greater than 5 min $(\mathrm{OR} 2.0 ; \mathrm{p}=0.014)$, performing a physical examination (OR $1.7 ; \mathrm{p}=0.019)$ or contact with a ventilator (OR 1.8; $\mathrm{p}=0.014)$ were similarly significant in raising the likelihood or risk of transfer of MDR bacteria but at rates lower than the rate observed for a positive environmental culture [49]. Intuition would suggest transfer was greater when interacting with a patient. However, the higher risk associated with a positive environmental culture serves to reinforce the importance that the microbial burden of the built clinical environment represents to the set of circumstances required for colonization and infection of patients while hospitalized.

\subsubsection{Risk to Patient When Prior Room Occupant Colonized or Infected with Epidemiologically Important Organisms}

Even with environmental cleaning, studies have suggested that certain organisms can be transmitted to the subsequent occupants in the setting of patient care. Specifically, methicillin resistant Staphylococcus aureus (MRSA), vancomycin resistant enterococci (VRE), C. difficile, and Gram negative pathogens have been implicated. In a study by Martinez, and others in 2003 an epidemiologic link was 
made between contaminated surfaces by VRE and subsequent VRE infection [46]. In another study where the environments of patients colonized or infected with VRE were evaluated upwards of $37 \%$ of the environmental samples collected were found to harbor VRE [31]. The samples included patient gowns, medical equipment used for care, as well as environmental surfaces [31]. Controlling the spread of VRE to subsequent room occupants is challenging in that this microbe can be resistant to the disinfectants used for routine and terminal cleaning; even the use of bleach-based products have been reported to fail in their ability to eradicate the microbe from surfaces [22, 24] (See also Chap. 9).

Independent of cleaning, the issue of transference of pathogens from the environment to subsequent occupants can be inferred from studies demonstrating the long-term survival of the microbes on surfaces within the built environment. MRSA and other nosocomial pathogens, including VRE and $C$. difficile can survive for months on dry surfaces (Chap. 2 and ref [42]). MRSA has been documented for its ability to survive within hospital dust for up to a year [89]. Further, frequently touched hospital surfaces, such as doorknobs, have been implicated as reservoirs from which pathogens can be routinely recovered and thus transferred [56]. MRSA, like VRE, is ubiquitous in the hospital environment, especially in the vicinity of patients known to be colonized or infected [22, 24]. The chief method of spread is poor compliance with infection control measures, such as hand hygiene, by healthcare workers. Several studies have described endemic and epidemic contamination of the environment with MRSA. A recent review by Dancer and colleagues found that the site contamination mean for common objects in the patient's room with MRSA was $37 \%$, with high percentages found for such surfaces as overbed tables $(40 \%)$, bed rails (27\%), and other furniture (27\%) [23].

The risk of acquiring MRSA or VRE by a patient being admitted into a room that was previously occupied by a patient known to harbor MRSA or VRE was described by Huang and colleagues [37]. The added risk of acquisition of MRSA to the 10,151 'eligible' patients examined by their study was found to increase by an adjusted odds ratio of 1.4 ( $\mathrm{p}=0.04)$. Specifically, amongst the patients whose prior room occupant was MRSA positive $(n=1,454), 3.9 \%$ of this cohort acquired MRSA, while only $2.9 \%$ of the patients who occupied a room previously housing a MRSA negative patient $(n=8697)$ acquired MRSA. A similar risk profile of acquisition of the drug resistant microbe was similarly observed with VRE. Here $4.5 \%$ of patients who occupied a room that previously housed a VRE positive patient $(n=1,291)$ developed VRE while the infection rate in patients housed in rooms previously occupied by a VRE negative patient $(n=9,058)$ had an attack rate of $2.8 \%$ (adjusted odds ratio of $1.4 ; \mathrm{p}=0.02$ ). The authors concluded that acquisition from previous occupants accounted for $40 \%$ increased odds of transmission of MRSA and VRE strongly suggesting a role for environmental contamination, despite room cleaning methods that exceeded the national standard [37]. A review of the topic of the risk of nosocomial pathogen acquisition from prior room occupants was recently published [58]. Here Otter and colleagues reviewed the increased risk associated with other MDR microbes. Again the trend was the same. Patients who occupied rooms where the former patient was infected or colonized 
with Pseudomonas aeruginosa or A. baumannii [55], or $C$. difficile [81] resulted in a similar increase risk of acquiring the previous occupants pathogen.

A study in 2011 showed that a prior room occupant with a CDI was a significant risk factor for CDI acquisition by the subsequent occupant [81]. This spore-forming anaerobic bacterium can survive for many months on hospital surfaces and is recalcitrant to usual cleaning methods [36]. Studies have shown very high environmental surface contamination rates, particularly in areas within close proximity to the patient. In a trial conducted in France, approximately $25 \%$ of healthcare workers who were caring for patients with a CDI were found to have $C$. difficile spores associated with their hands [43]. The authors concluded that contamination of the hands was positively associated with exposure to fecal soiling and lack of glove use.

Several Gram-negative nosocomial pathogens, such as $P$. aeruginosa and A. baumannii, increasingly associated with multi-drug resistance, have similarly been recovered from high touch surfaces such as beds, tables, and infusion pumps [5]. Outbreaks, thought to have occurred because of patient to patient spread of MDR Gram negatives, can be devastating to patients and hospitals, resulting in high numbers of cases and high morbidity and mortality. Responses have included robust and aggressive approaches towards infection control often including enhanced environmental cleaning and in extreme cases closure of the affected unit or substantial areas of the hospital [25, 27, 45]. Fortunately, the majority of the clinically relevant Gram-negative microbes associated with the built clinical environment are not viable after drying. Half-lives routinely encountered are $7 \mathrm{~h}$ or less [36].

An emerging nosocomial fungal pathogen, which has become a common cause of central line associated bacteremia in healthcare, is Candida albicans. There are fewer studies documenting the extent of environmental contamination with fungi; however, C. albicans has been shown to be able to survive anywhere from 3 days to up to 4 months on inanimate surfaces [42]. The majority of Candida infections are likely from endogenous sources. However, through molecular typing, evidence of transmission via environmental sources has been suggested; identical strain types were recovered from patients infected with Candida and from hospital surfaces from the rooms of the affected patients [88].

There are several classes of pathogenic viruses that can be found on hospital surfaces. Respiratory viruses such as influenza, coronavirus, and rhinovirus can persist on surfaces for a few days [42]. Viable influenza virus can be transferred from surface to skin, leading to the potential transfer to patients [36]. Gastrointestinal tract viruses, such as rotavirus and astrovirus, can persist for around 2 months [42]. Rotavirus is a well-known cause of gastrointestinal illness outbreaks, especially in day care centers where it is spread through contamination of toys [36]. Norovirus has been shown in several studies to be consistently transferred to frequently touched sites in a hospital, such as door handles and telephones [24]. Closure of units and deep environmental cleaning similar in scope, time and expense seen with MDR-Gram negative outbreaks are often needed to control Norovirus outbreaks in hospitals. 


\subsection{No-Touch Disinfection Technologies}

In summary, since the seminal paper by Weinstein in 1991, substantial evidence implicating the environment as a continuous source of risk for the acquisition of HAI has accumulated to such an extent that there now exists significant interest in learning how to manage and provide best-practice applications for infection control for hospitals $[8,12,13,15]$. Evident from the previous discussion, microbes have an intrinsic ability to survive and ultimately colonize common touch surfaces where acquisition and transport from surfaces to humans is common. Healthcare workers have the potential to transfer these microbiological contaminants not only from patient to patient but amongst themselves and back to surfaces, refreshing or adding to the complexity of the microbial reservoir involved in transmission. There have been many studies looking at the control of contamination of common hospital touch surfaces both from hand to surface contact and vice versa. Investigators have shown that the gloves of nurses frequently collected viable MRSA after touching inanimate objects near colonized patients [16]. In concert with aggressive hand hygiene campaigns recent hygiene guidelines specifically recommend that particular attention be paid to the disinfection of patient-care surfaces, especially surfaces designated "high touch objects" (HTOs) as a target of infection prevention and control [78]. The guidelines note that such objects could potentially contribute to secondary transmission by contaminating hands of healthcare workers (HCWs) or by contacting medical equipment that subsequently contacts patients [8, 29, 64, 67, $72,73,90]$. Routine or daily cleaning coupled with cleaning immediately after patient discharge (terminal cleaning) of the surfaces and objects within the room with subsequent application of a hospital grade disinfectant has been an accepted method for controlling and limiting the spread of infectious agents [68]. A concentration of between 2.5 and 5 aerobic CFU per square centimeter has been proposed as the benchmark where bacterial levels below this value are considered to represent a minimum of risk while concentrations greater are suggestive of an increased risk of HAI acquisition [22, 44].

No touch solutions for the disinfection of at-risk environments within healthcare settings are quickly gaining acceptance as technologies that have been found to be an effective and comprehensive addition to systems-based solutions for infection control. The technologies have been studied in concert with aggressive hand hygiene campaigns, appropriate routine and terminal cleaning of patient care environments, and an active surveillance and isolation protocol for patients entering care who are already colonized with VRE, MRSA, $C$. difficile or other multi-drug resistant microbes such as Klebsiella pneumoniae carbapenemase (KPC). As a consequence of this, one is left to wonder whether or not the antimicrobial effectiveness is providing an additive effect or whether the antimicrobial effectiveness of these 'no-touch technologies' are acting synergistically.

As the name suggests, no-touch technologies do not come in direct contact with colonized, contaminated or soiled surfaces. Rather, they distribute their microbiocidal activity through the atmosphere by either delivering a lethal 
concentration of electromagnetic energy in the ultraviolet spectrum or by the real-time distribution of reactive oxygen species, such as hydrogen peroxide, singlet oxygen, hydroxyl radical or oxyanions. In general both systems have been found to effectively reduce the concentration of microbes by at least $4 \operatorname{logs}_{10}$ [34]. Both systems have their limitations (See Chap. 9). Each requires skilled labor to place the equipment and commence the disinfection cycle in the location subjected to disinfection.

The disinfection reach of ultraviolet light is subject to the effects of shadowing and 'cornering'. This typically requires that the equipment be placed in the center of the room to insure uninform distribution of the lethal ultraviolet energy. Additionally, the room must be vacant and any associated ultraviolet energy need be prevented from leaking into areas occupied by people as the ultraviolet (UV) light energy can damage eyesight and result in skin burns. The energy can also shorten the life of equipment in the room as routine exposure to UV light can accelerate decay by increasing the brittleness of many of the plastics used in the fabrication of healthcare associated equipment.

The use of an automated UV-C light emitting system for the inactivation of VRE, $C$. difficile and species of Acinetobacter has been found to be effective in debulking the built environment of these pathogens. In one study, employing an automated emitter in two hospitals, the concentrations of bacteria were reduced for all 9 of the environmental sites tested and occurred regardless of whether the sampled location was in direct or indirect line of sight of the UV source [3]. Further, the extent of the reduction to the microbial burden was found to be significant for VRE and C. difficile but not Acinetobacter spp. [3]. However, the data were sufficiently compelling to lead the authors to conclude that the use of an automated UV-C no-touch disinfection device can lead to a decrease in the bioburden of important nosocomial pathogens in 'real-world' active clinical environments [3].

Another multi-hospital intervention used a pulsed xenon based UV delivery mechanism in concert with screening and hand hygiene education, together, the three were able to significantly reduce $(56 \%, \mathrm{p}=0.001)$ the incidence of hospital associated MRSA infections in the study population [82]. Given that this was a bundled intervention the contribution of the individual components of the bundle cannot be discerned. However, the data do reinforce the common belief that any effective infection control program requires a systematic approach in order to be effective.

As early as 1990 vapor phase hydrogen peroxide (HPV) has been advocated as an effective surface decontaminant and sterilant [40]. In the intervening years a number of devices have been developed to deploy this disinfectant/sterilant as a vapor into the built clinical environment. In one study conducted by Passaretti and others, an evaluation of the environmental and clinical impact of this no-touch technology was assessed [59]. In a 30 month prospective cohort intervention trial involving 6 high risk units from a 994 bed tertiary care hospital, they learned that patients admitted to rooms decontaminated using HPV were $64 \%$ less likely $(\mathrm{p}<0.001)$ to acquire any multidrug resistant microbe and $80 \%$ less likely to acquire $\operatorname{VRE~}(\mathrm{p}<0.001)$ after adjusting for other factors [59]. Again, the complexity inherent to the transmission and distribution of microbes within the built environment, coupled with the stochastic nature of care, well illustrates that the risk of acquiring $C$. difficile, MRSA, and 
multidrug-resistant Gram-negative rods were reduced, but failed to reach significance. However, in spite of the failure to reach significance the effectiveness of this no-touch infection control solution was able to significantly alter the proportion of rooms environmentally contaminated with MDRs. Here the concentration of MDRs in the HPV treated units were significantly reduced (relative risk, $0.65, p=0.03$ ), but not on non-HPV treated units leading the authors to conclude that the use of HPV can reduce the risk of acquiring MDRs compared with standard cleaning protocols [59].

In spite of the success demonstrated here and in other studies [14, 21] vaporphase disinfection of the built environment has limitations in that the ventilation to the room must be controlled/and or limited for the duration of the disinfection cycle. This time can vary depending upon the concentration of peroxide or disinfecting gas used. These two technologies, HPV and UV, have been found to be effective for the disinfection of inanimate objects and surfaces. However, neither technology is intended as a substitute for cleaning or for the removal of soil from the resident objects and surfaces within the built patient care environment (see also Chap. 9). An appropriately trained environmental service team must accomplish cleaning, with subsequent disinfection of the built environment.

\subsection{Antimicrobial Copper: A Continuously Active No-Touch Disinfection Solution for Healthcare}

Recently, we have begun to witness the incorporation of another 'no-touch' technology. However, unlike UV and vapor phase oxygen radicals $\left(\mathrm{H}_{2} \mathrm{O}_{2}\right)$ that distribute their antimicrobial activity through the atmosphere, this technology requires the microbe come in contact or be in close proximity with the material in order to facilitate its antimicrobial activity. In contrast to UV and HVP, once placed, this no-touch system simply requires that the fugitive microbe come in contact with the surface in order to effect disinfection. Thus, the inactivation or killing of the microbe does not require any user intervention once deployed. One such example of this type of no-touch technology is solid antimicrobial copper. The resident microbial burden associated with the built environment is continuously reduced through the strategic placement of solid copper surfaces onto critical high touch surfaces within the patient care setting [75].

Copper has been used by humans for millennia, first as tools and then as a measure to fight the spread of infectious agents. Metallic copper intrinsically displays a strong antibacterial activity in aquatic systems $[2,38]$ as well as on dry surfaces $[32,54,96$, 102, 104]. In 2008 the United States Environmental Protection Agency (EPA) registered five families of copper-containing alloys as antimicrobial, establishing that products manufactured from one of these registered alloys can make public health claims wherein the label indication states that the alloys kill greater than $99.9 \%$ of bacteria within $2 \mathrm{~h}$ of exposure [87]. It is anticipated that the solid antimicrobial copper surfaces will remain microbiocidal for the life of the product ( $>10$ years). A variety of controlled studies have looked at the antimicrobial activity 
Table 4.1 Microorganisms sensitive to the antimicrobial properties intrinsic to solid metallic copper

\begin{tabular}{|c|c|c|}
\hline Microbe & Reference(s) & EPA registered \\
\hline$\overline{\text { Acinetobacter baumanii }}$ & [47] & \\
\hline Aspergillus flavus & [96] & \\
\hline Aspergillus fumigatus & [96] & \\
\hline Aspergillus spp. & [96] & \\
\hline Campylobacter jejuni & [28] & \\
\hline Candida albicans & {$[47,96]$} & \\
\hline Clostridium difficile & [97] & \\
\hline Clostridium difficile spores & [97] & \\
\hline Carbapenem-resistant Enterobacteriaceae (CRE) & [84] & \\
\hline Enterobacter aerogenes & [87] & $*$ \\
\hline E. coli $0157: H 7$ & {$[87,104]$} & * \\
\hline Escherichia coli-NDM1 & [93] & \\
\hline Fusarium culmonium & [96] & \\
\hline Fusarium oxysporium & [96] & \\
\hline Fusarium solani & [10] & \\
\hline Fusarium spp. & [96] & \\
\hline Influenza A (including H1N1) & [53] & \\
\hline Klebsiella pneumoniae & [47] & \\
\hline Klebsiella pneumoniae-NDM-1 & [93] & \\
\hline Legionella pneumonphila & {$[65,66]$} & \\
\hline Listeria monocytogenes & [105] & \\
\hline Methicillin resistant Staphylococcus aureus (MRSA) & [87] & $*$ \\
\hline Methylobacterium spp. & [76] & \\
\hline Mycobacterium tuberculosis & [47] & \\
\hline Norovirus & [94] & \\
\hline Penicillium chrysogenum & [96] & \\
\hline Penicillium spp. & [96] & \\
\hline Pseudomonas aurginosa & {$[87,96]$} & $*$ \\
\hline Rhinovirus & [11] & \\
\hline Rotavirus & [11] & \\
\hline Salmonella enterica & [28] & \\
\hline Salmonella typhi & {$[79,80]$} & \\
\hline Spingomonoas spp. & [76] & \\
\hline Staphylococcus auerus & [87] & $*$ \\
\hline Serratia marcescens & [11] & \\
\hline Vancomycin resistant Enterococci (VRE) & [87] & $*$ \\
\hline Vibrio cholerae & {$[79,80]$} & \\
\hline
\end{tabular}

*Designates EPA registered

of copper surfaces against specific human pathogens [54, 63, 92, 98, 102, 104, 105]. In fact solid copper surfaces have been found to be microbicidal to well over 30 bacteria, fungi and viruses. Of the microbes listed in Table 4.1, five were evaluated in the studies used to grant the public health registration by the United States EPA. The public health claims granted illustrate the robust nature of the antimicrobial activity. Alloys granted registration contain greater than $60 \%$ metallic copper and 
were found to continuously kill greater than $99.9 \%$ of Gram-negative and Grampositive bacteria within $2 \mathrm{~h}$ of exposure even after repeated contamination illustrating how solid copper surfaces will inhibit the buildup of microorganisms between routine cleaning and sanitizing steps.

The public health claims attributed to solid copper have been evaluated to limit the bacterial burden found on commonly touched surfaces and objects in active healthcare environments. In a recent hospital trial bacterial reductions up to one third were recorded using copper alloys in place of plastic or aluminum surfaces on light switches, door knobs and push plates [48]. Casey and others [20] observed a median microbial reduction of between 90 and $100 \%$ ( $\left.\log _{10} 1.95-2.0\right)$ on copper surfaced push plates, faucet handles, and toilet seats while Schmidt and colleagues demonstrated significantly lower bacterial burdens on six HTOs, averaging an $83 \%\left(\log _{10} 1.93\right)$ reduction for all of the objects over the course of a 43 month multi-center trial [75].

Current cleaning methods can effectively remove pathogens from surfaces but studies have shown that more than half of the trial surfaces were not adequately terminally cleaned, and became re-contaminated within minutes $[4,17]$. The rails of hospital beds, as a consequence of coincident interactions with patients, HCWs, and visitors are one of the most frequently touched items found in the built patient care environment. Schmidt and colleagues found when they quantitatively assessed the bacterial burden present on bed rails that, through the surfacing of the rail with metallic copper, the concentration of bacteria resident on this frequently touched surface was continuously at or below the threshold representing a risk of transfer regardless of whether or not the surface was measured before or after routine cleaning [77].

Further, the environmental monitoring of bed frames has consistently shown that the rails of hospital beds typically exceed a suggested threshold of risk more than any other object in the patient's room $[4,50,75,77,103]$. It was evident that bed rails covered with solid copper are able to augment cleaning and thereby continuously support the control of the concentration of associated aerobic bacteria. This observation was consistently maintained in spite of the kinetic nature of care present in the environment of the ICU. Lower risk concentrations, less than $2.5 \mathrm{CFU} / \mathrm{cm}^{2}$, were associated with over $83 \%$ of the sampled beds [77]. Further, MRSA and VRE were absent from all but 7 of the 3,938 copper objects sampled arguing that the risk mitigation provided by copper surfaces might be greater than the average concentrations reported suggest [77].

Weber and Rutala [99] in their commentary of the evaluation of no-touch copper conducted by Karpanen and colleagues argued that it was impractical or impossible to coat each of the environmental surfaces with copper [39]. However, the data provided by Schmidt and colleagues suggest that the strategic placement of solid copper surfaces in high touch areas is key, and offers a novel strategy to limit the bacterial burden on a continuous basis [75]. Copper-alloyed surfaces offer a continuous way to limit and/or control the environmental burden. Hospital and environmental services need not perform additional steps, follow complex treatment algorithms, obtain "buy-in" from other providers or require additional training or oversight. The other 'no touch' methods presently in wide scale use for room 


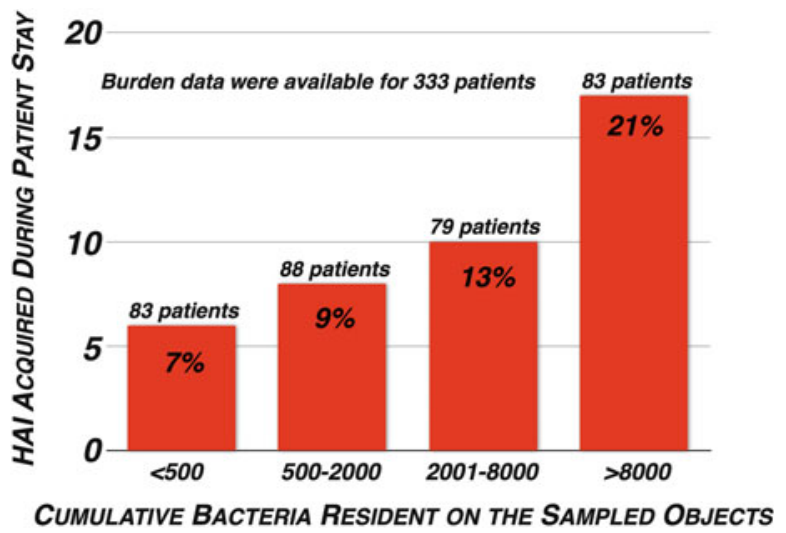

Fig. 4.3 Concentration of bacteria associated with high touch objects associated with the built clinical environment and HAI are linked. A significant association $(p=0.038)$ was observed between the microbial burden and the incidence of HAI acquired during patient stay. Briefly, the burden data from 333 patients were evaluated in the context of an acquisition of a HAI. It was found that $89 \%$ of HAI occurred amongst patients cared for in rooms where the burden observed on six high touch objects exceeded a concentration of $500 \mathrm{CFU}$. Percentage values listed for the individual quartiles are reflective of the percentage quartile population acquiring an HAI (Adapted after the figure of Salgado and colleagues [70])

disinfection rely on discontinuous modalities of application in order to reduce the environmental bacterial burden [34]. Hydrogen peroxide vapor is introduced as a gas into a sealed room. Ultraviolet light achieves its effectiveness through the transient transmission of germicidal radiation within an unoccupied room. Consequently, like the EPA registered disinfectants regularly used to disinfect patient rooms subsequent to cleaning, both UV and HPV will likely suffer from the same limitations of the rapid restoration of the bacterial burden intrinsic to high touch objects.

In addressing the question of whether or not the strategic placement of copper might ameliorate the rate with which HAI are acquired, Salgado and colleagues [70] found from the conduct of a multi-center trial that the limited placement of copper as described by Schmidt and colleagues [75] resulted in a significant reduction to the HAI rate and/or MRSA or VRE colonization rate in medical intensive care rooms (ICU). The collective rate for HAI infection or MRSA/VRE colonization was found to be significantly lower by $42 \%(7.1 \%)$ in the copper arm of the study when compared against the $(12.3 \%)$ rate observed in the control rooms $(\mathrm{p}=0.02)$. When the data were considered separately for HAI alone, the rate of infection was significantly reduced $(58 \%)$ from 8.1 to $3.4 \%(\mathrm{p}=0.013)$.

More importantly, these investigators were able to demonstrate that burden and infection were directly linked. In the analysis of the quartile distribution of HAIs stratified by microbial burden measured in the ICU rooms during the patient's stay they learned that there was a significant association between burden and HAI risk $(\mathrm{p}=0.038)$, with $89 \%$ of HAI occurring among patients cared for in a room with a burden of more than $500 \mathrm{CFU}$ (Fig. 4.3) [70]. 


\subsection{Postulated Mechanism of Action of Solid Metallic Cooper}

The mechanism of action associated with the antimicrobial properties of solid copper surfaces is multifaceted (Chap. 6). Upon coming in contact with the metallic copper surfaces of objects, the electron potential of the microbe in concert with copper facilitates a cascade of irreversible events leading to the rapid death of the bacterium. Given the inherent ability of solid metallic copper and its alloys containing greater than $60 \%$ copper for the conduction of electricity, the electrons resident in the membrane of the bacterium that are sufficiently close to the metallic surface coupled with the high flux required by living cells result in the rapid collapse of the proton motive force of the microbe. The subsequent dissipation of the proton motive force (PMF) has been observed through the use of dyes that measure the membrane potential. Warnes and others have reported on this observation on numerous occasions for both Gram positive and Gram negative bacteria [91-93, 95]. Subsequent to the collapse of the membrane potential a concomitant production of free radicals immediately develops within the cytoplasm of the bacterium. The free radicals facilitate the peroxidation of the membrane, bleaching of cellular proteins and the cleavage and subsequent complete destruction of the nucleic acids resident in the cytoplasm of the effected microbes. Additionally upon peroxidation of the membrane there is a loss of membrane integrity resulting in the subsequent leakage of the cytoplasm from the cell and diffusion mediated transport of copper ions into the cytoplasm. The copper ions then act in concert with the free radicals resulting in a Fenton reaction that leads to further irreparable damage to the cell [91]. The entire process occurs quickly resulting in the collapse of a population within minutes. Thus, the likelihood that the population will develop resistance to this multifaceted mechanism of death is unlikely. There have been reports in the literature of bacteria being isolated from copper coins but upon challenging the 'resistant' isolates they were found to be uniformly sensitive to metallic copper [71]. A likely explanation for their recovery from the surface is likely a consequence of a failure to sufficiently collapse the PMF of the entire community as either a function of proximity of the surviving microbes to the metallic surface or the absence of sufficient electron flux through the membrane to initiate the cascade required for death.

\subsection{Use of Copper Surfaces in Healthcare}

In the study conducted by Salgado and colleagues, six highly touched objects within the ICUs were selected based from a limited survey where the contact surfaces being the most highly contaminated were identified. The six items were then fabricated from a variety of antimicrobial copper alloys, where the criteria for alloy selection were reflective of the ability of the antimicrobial alloys to be readily 

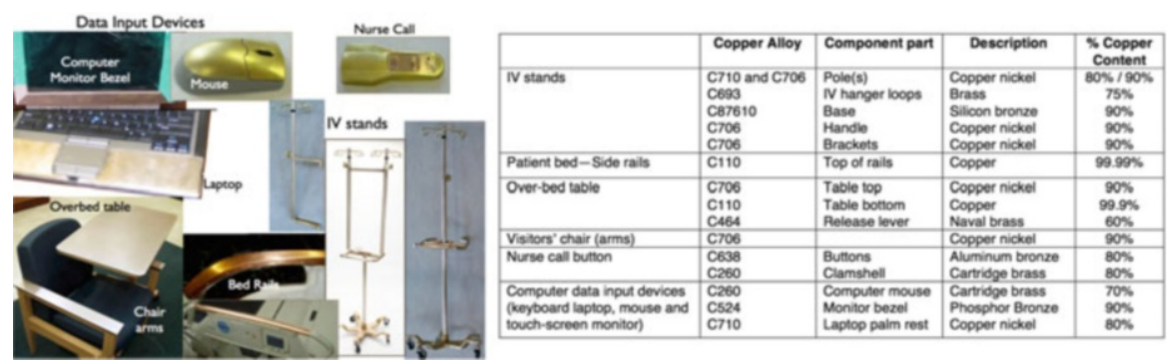

Fig. 4.4 EPA registered antimicrobial cooper alloys used in the fabrication or surfacing of high touch items. Items were fabricated from a variety of EPA registered antimicrobial copper alloys as listed. The criterion used to select an alloy was reflective of the ability of the antimicrobial alloy to be readily fabricated into that particular component and withstand the rigors of healthcare

fabricated into that particular component (Fig. 4.4). Properties of strength and durability were operationally defined such that the resulting component would be able to withstand the rigors placed on the finished goods within the built environment of an active clinical setting and for the ability of the materials to withstand standard hospital cleaners, including sodium hypochlorite. Additionally, the surface finish was to provide consistent wear and aesthetics over the lifespan of the product. All of the copper alloys used for component fabrication were made from solid alloys registered with the EPA [87]. Subsequent to the published report, manufacturers have introduced numerous products fabricated from EPA registered solid copper that meet or exceed the criteria used by the referenced authors $[70,74,75]$.

From a design standpoint, it is important to note that these results were 'additive' to other infection-control implementations already in place. Single patient rooms, hand-washing sinks, hand sanitizing alcohol dispensers, contact precautions required of MRSA and VRE carriers/infected patient(s), and an active hand hygiene staff education program were already in place in the units of the hospitals studied. Should these conclusions expand to other areas of the hospital, then employing inherently antimicrobial surfaces could represent a significant enhancement to mitigating infectious bacteria within hospitals. For example, by instituting a 'best practices' approach that implemented cleaning and hand hygiene designs and protocols, the California's Healthcare-Associated Infection Prevention Initiative showed a reduction of HAI by $3.2 \%$. With many of these best practices already in place, the initial findings from the clinical trials are showing an additional double-digit reduction in infections.

Although the relative infection rate in the medical ICUs where the clinical effectiveness of antimicrobial copper surfaces were evaluated is generally higher than hospitals at large, patients in ICUs are typically not mobile, and their interaction with the built environment is very limited. Consequently, items where antimicrobial copper alloys might have been easily incorporated, e.g. grab bars, sinks, faucets, paper dispensers, shelves and towel racks were not present. The further evaluation of antimicrobial copper surfaces is warranted beyond the medical ICU to include, but not be limited to, the effect of inherently antimicrobial materials in 
general wards where patients have greater interaction with other objects in the built environment. Similarly, investigations should also be conducted in emergency and recovery rooms, in hospital rehabilitation units, pediatric and neonatal units, dialysis centers, burn units, transplant units and cancer centers with immunecompromised patients. At issue is the central theme that antimicrobial copper surfaces continuously and passively limit the concentration of bacteria within the built environment. Salgado and colleagues were able to demonstrate that infections were correlated with burden. Thus, other healthcare environments that may arguably receive less day-to-day hygienic oversight than hospital patient rooms, such as visiting area, long-term care facilities, long-term rehab centers, outpatient clinics and elder care facilities should also be investigated as they too may directly benefit from the antimicrobial activity of copper.

\subsection{Summary}

The study of pathogen transmission in the hospital and the impact of colonization and infection with nosocomial organisms have established the epidemiologic importance of the environmental microbial burden associated with the built clinical environment. These studies have outlined the complexity of this concept and have led to robust recommendations for infection prevention that have undoubtedly prevented undo morbidity and mortality. However, with renewed interest and study the risk contribution provided by the built environment towards patient care warrants a better understanding of the dynamics of colonization and infection. Through our discussion here we hope that we have been able to identify potential avenues for improvement with adjunctive use of newer technologies. These include the use of UV light and HPV disinfection, and the potential value of the use of solid antimicrobial copper surfaces.

Through a multifaceted and continuously active mechanism of action, solid copper surfaces placed in key locations within the patient room can significantly reduce the overall microbial burden; have demonstrated their ability to continuously maintain this concentration at a level representing a minimal risk for HAI acquisition and most importantly, have translated meaningful benefit to patients by their association with significant reduction of HAI. Further study to identify the optimal amount of copper surfaces needed as well as the optimal placement in rooms and areas within healthcare facilities is necessary to fully understand the potential impact.

\section{References}

1. Aiello AE, Larson EL (2002) What is the evidence for a causal link between hygiene and infections? Lancet Infect Dis 2:103-110

2. Albright LJ, Wilson EM (1974) Sub-lethal effects of several metallic salts organic compound combinations upon the heterotrophic microflora of a natural water. Water Res 8:101-105 
3. Anderson DJ, Gergen MF, Smathers E, Sexton DJ, Chen LF, Weber DJ, Rutala WA (2013) Decontamination of targeted pathogens from patient rooms using an automated ultraviolet-Cemitting device. Infect Control Hosp Epidemiol 34:466-471

4. Attaway HH 3rd, Fairey S, Steed LL, Salgado CD, Michels HT, Schmidt MG (2012) Intrinsic bacterial burden associated with intensive care unit hospital beds: effects of disinfection on population recovery and mitigation of potential infection risk. Am J Infect Control 40:907-912

5. Aygün G, Demirkiran O, Utku T, Mete B, Ürkmez S, Yılmaz M, Yaşar H, Dikmen Y, Öztürk R (2002) Environmental contamination during a carbapenem-resistant Acinetobacter baumannii outbreak in an intensive care unit. J Hosp Infect 52:259-262

6. Bache SE, Maclean M, Gettinby G, Anderson JG, MacGregor SJ, Taggart I (2013) Quantifying bacterial transfer from patients to staff during burns dressing and bed changes: implications for infection control. Burns 39:220-228

7. Barker J, Vipond IB, Bloomfield SF (2004) Effects of cleaning and disinfection in reducing the spread of Norovirus contamination via environmental surfaces. J Hosp Infect 58:42-49

8. Bhalla A, Pultz NJ, Gries DM, Ray AJ, Eckstein EC, Aron DC, Donskey CJ (2004) Acquisition of nosocomial pathogens on hands after contact with environmental surfaces near hospitalized patients. Infect Control Hosp Epidemiol 25:164-167

9. Blowers R, Hill J, Howell A (1973) Shedding of Staphylococcus auerus by human carriers. In: Hers JFP, Winkler KC (eds) Airborne transmission and airborne infection. Oosthoek, Utrecht, p 432

10. Blythe D, Keenlyside D, Dawson SJ, Galloway A (1998) Environmental contamination due to methicillin-resistant Staphylococcus aureus (MRSA). J Hosp Infect 38:67-69

11. Borkow G, Monk A (2012) Fighting nosocomial infections with biocidal non-intrusive hard and soft surfaces. World J Clin Infect Dis 2:77-90

12. Boyce JM (2007) Environmental contamination makes an important contribution to hospital infection. J Hosp Infect 65(Suppl 2):50-54

13. Boyce JM (1997) Vancomycin-resistant enterococcus. Detection, epidemiology, and control measures. Infect Dis Clin N Am 11:367-384

14. Boyce JM, Havill NL, Otter JA, McDonald LC, Adams NM, Cooper T, Thompson A, Wiggs L, Killgore G, Tauman A, Noble-Wang J (2008) Impact of hydrogen peroxide vapor room decontamination on Clostridium difficile environmental contamination and transmission in a healthcare setting. Infect Control Hosp Epidemiol 29:723-729

15. Boyce JM, Pittet D (2002) Guideline for Hand Hygiene in Health-Care Settings: recommendations of the Healthcare Infection Control Practices Advisory Committee and the HICPAC/ SHEA/APIC/IDSA Hand Hygiene Task Force. Infect Control Hosp Epidemiol 23:S3-S40

16. Boyce JM, Potter-Bynoe G, Chenevert C, King T (1997) Environmental contamination due to methicillin-resistant Staphylococcus aureus: possible infection control implications. Infect Control Hosp Epidemiol 18:622-627

17. Carling PC, Bartley JM (2010) Evaluating hygienic cleaning in health care settings: what you do not know can harm your patients. Am J Infect Control 38:S41-S50

18. Casanova LM, Rutala WA, Weber DJ, Sobsey MD (2012) Effect of single- versus doublegloving on virus transfer to health care workers' skin and clothing during removal of personal protective equipment. Am J Infect Control 40:369-374

19. Casewell M, Phillips I (1977) Hands as route of transmission for Klebsiella species. Br Med J 2:1315-1317

20. Casey AL, Adams D, Karpanen TJ, Lambert PA, Cookson BD, Nightingale P, Miruszenko L, Shillam R, Christian P, Elliott TS (2010) Role of copper in reducing hospital environment contamination. J Hosp Infect 74:72-77

21. Cooper T, O'Leary M, Yezli S, Otter JA (2011) Impact of environmental decontamination using hydrogen peroxide vapour on the incidence of Clostridium difficile infection in one hospital Trust. J Hosp Infect 78:238-240 
22. Dancer SJ (2004) How do we assess hospital cleaning? A proposal for microbiological standards for surface hygiene in hospitals. J Hosp Infect 56:10-15

23. Dancer SJ (2008) Importance of the environment in meticillin-resistant Staphylococcus aureus acquisition: the case for hospital cleaning. Lancet Infect Dis 8:101-113

24. Dancer SJ (2009) The role of environmental cleaning in the control of hospital-acquired infection. J Hosp Infect 73:378-385

25. Das I, Lambert P, Hill D, Noy M, Bion J, Elliott T (2002) Carbapenem-resistant Acinetobacter and role of curtains in an outbreak in intensive care units. J Hosp Infect 50:110-114

26. deForest GK, Kerr LM (1945) A case of eczema as a source of a streptococcal epidemic. Am J Med Sci 209:752-758

27. Enoch DA, Summers C, Brown NM, Moore L, Gillham MI, Burnstein RM, Thaxter R, Enoch LM, Matta B, Sule O (2008) Investigation and management of an outbreak of multidrugcarbapenem-resistant Acinetobacter baumannii in Cambridge, UK. J Hosp Infect 70:109-118

28. Faundez G, Troncoso M, Navarrete P, Figueroa G (2004) Antimicrobial activity of copper surfaces against suspensions of Salmonella enterica and Campylobacter jejuni. BMC Microbiol 4:19

29. Favero MS, Bond WW (2001) Chemical disinfection of medical and surgical materials. In: Block SS (ed) Disinfection, sterilization, and preservation. Lippincott Williams \& Wilkins, Philadelphia, pp 881-917

30. Fryklund B, Tullus K, Burman LG (1995) Survival on skin and surfaces of epidemic and non-epidemic strains of enterobacteria from neonatal special care units. J Hosp Infect 29:201-208

31. Gould FK, Freeman R (1993) Nosocomial infection with microsphere beds. Lancet 342:241-242

32. Grass G, Rensing C, Solioz M (2011) Metallic copper as an antimicrobial surface. Appl Environ Microbiol 77:1541-1547

33. Hambraeus A (1973) Transfer of Staphylococcus aureus via nurses' uniforms. J Hyg (Lond) 71:799-814

34. Havill NL, Moore BA, Boyce JM (2012) Comparison of the microbiological efficacy of hydrogen peroxide vapor and ultraviolet light processes for room decontamination. Infect Control Hosp Epidemiol 33:507-512

35. Hooton TM, Bradley SF, Cardenas DD, Colgan R, Geerlings SE, Rice JC, Saint S, Schaeffer AJ, Tambayh PA, Tenke P, Nicolle LE, A Infectious Diseases Society of America (2010) Diagnosis, prevention, and treatment of catheter-associated urinary tract infection in adults: 2009 International Clinical Practice Guidelines from the Infectious Diseases Society of America. Clin Infect Dis 50:625-663

36. Hota B (2004) Contamination, disinfection, and cross-colonization: are hospital surfaces reservoirs for nosocomial infection? Clin Infect Dis 39:1182-1189

37. Huang SS, Datta R, Platt R (2006) Risk of acquiring antibiotic-resistant bacteria from prior room occupants. Arch Intern Med 166:1945-1951

38. Jonas RB (1989) Acute copper and cupric ion toxicity in an estuarine microbial community. Appl Environ Microbiol 55:43-49

39. Karpanen TJ, Casey AL, Lambert PA, Cookson BD, Nightingale P, Miruszenko L, Elliott TS (2012) The antimicrobial efficacy of copper alloy furnishing in the clinical environment: a crossover study. Infect Control Hosp Epidemiol 33:3-9

40. Klapes NA, Vesley D (1990) Vapor-phase hydrogen peroxide as a surface decontaminant and sterilant. Appl Environ Microbiol 56:503-506

41. Klevens RM, Edwards JR, Richards CL Jr, Horan TC, Gaynes RP, Pollock DA, Cardo DM (2007) Estimating health care-associated infections and deaths in U.S. hospitals, 2002. Public Health Rep 122:160-166

42. Kramer A, Schwebke I, Kampf G (2006) How long do nosocomial pathogens persist on inanimate surfaces? A systematic review. BMC Infect Dis 6:130 
43. Landelle C, Verachten M, Legrand P, Girou E, Barbut F, Buisson CB (2014) Contamination of Healthcare Workers' Hands with Clostridium difficile Spores after Caring for Patients with C. difficile Infection. Infect Control Hosp Epidemiol 35:10-15

44. Malik RE, Cooper RA, Griffith CJ (2003) Use of audit tools to evaluate the efficacy of cleaning systems in hospitals. Am J Infect Control 31:181-187

45. Markogiannakis A, Fildisis G, Tsiplakou S, Ikonomidis A, Koutsoukou A, Pournaras S, Manolis EN, Baltopoulos G, Tsakris A (2008) Cross-transmission of multidrug-resistant Acinetobacter baumannii clonal strains causing episodes of sepsis in a trauma intensive care unit. Infect Control Hosp Epidemiol 29:410-417

46. Martinez JA, Ruthazer R, Hansjosten K, Barefoot L, Snydman DR (2003) Role of environmental contamination as a risk factor for acquisition of vancomycin-resistant enterococci in patients treated in a medical intensive care unit. Arch Intern Med 163:1905-1912

47. Mehtar S, Wiid I, Todorov SD (2008) The antimicrobial activity of copper and copper alloys against nosocomial pathogens and Mycobacterium tuberculosis isolated from healthcare facilities in the Western Cape: an in-vitro study. J Hosp Infect 68:45-51

48. Mikolay A, Huggett S, Tikana L, Grass G, Braun J, Nies DH (2010) Survival of bacteria on metallic copper surfaces in a hospital trial. Appl Microbiol Biotechnol 87:1875-1879

49. Morgan DJ, Rogawski E, Thom KA, Johnson JK, Perencevich EN, Shardell M, Leekha S, Harris AD (2012) Transfer of multidrug-resistant bacteria to healthcare workers' gloves and gowns after patient contact increases with environmental contamination. Crit Care Med 40:1045-1051

50. Mulvey D, Redding P, Robertson C, Woodall C, Kingsmore P, Bedwell D, Dancer SJ (2011) Finding a benchmark for monitoring hospital cleanliness. J Hosp Infect 77:25-30

51. Noble WC (1975) Dispersal of skin microorganisms. Br J Dermatol 93:477-485

52. Noble WC (1962) The dispersal of staphylococci in hospital wards. J Clin Pathol 15:552-558

53. Noyce JO, Michels H, Keevil CW (2007) Inactivation of influenza A virus on copper versus stainless steel surfaces. Appl Environ Microbiol 73:2748-2750

54. Noyce JO, Michels H, Keevil CW (2006) Potential use of copper surfaces to reduce survival of epidemic meticillin-resistant Staphylococcus aureus in the healthcare environment. J Hosp Infect 63:289-297

55. Nseir S, Blazejewski C, Lubret R, Wallet F, Courcol R, Durocher A (2011) Risk of acquiring multidrug-resistant Gram-negative bacilli from prior room occupants in the intensive care unit. Clin Microbiol Infect 17:1201-1208

56. Oie S, Hosokawa I, Kamiya A (2002) Contamination of room door handles by methicillinsensitive/methicillin-resistant Staphylococcus aureus. J Hosp Infect 51:140-143

57. Otter JA, Yezli S, French GL (2011) The role played by contaminated surfaces in the transmission of nosocomial pathogens. Infect Control Hosp Epidemiol 32:687-699

58. Otter JA, Yezli S, Salkeld JA, French GL (2013) Evidence that contaminated surfaces contribute to the transmission of hospital pathogens and an overview of strategies to address contaminated surfaces in hospital settings. Am J Infect Control 41:S6-S11

59. Passaretti CL, Otter JA, Reich NG, Myers J, Shepard J, Ross T, Carroll KC, Lipsett P, Perl TM (2013) An evaluation of environmental decontamination with hydrogen peroxide vapor for reducing the risk of patient acquisition of multidrug-resistant organisms. Clin Infect Dis $56: 27-35$

60. Pessoa-Silva CL, Dharan S, Hugonnet S, Touveneau S, Posfay-Barbe K, Pfister R, Pittet D (2004) Dynamics of bacterial hand contamination during routine neonatal care. Infect Control Hosp Epidemiol 25:192-197

61. Pittet D, Allegranzi B, Sax H, Dharan S, Pessoa-Silva CL, Donaldson L, Boyce JM, World Alliance for Patient Safety Who Global Patient Safety Challenge (2006) Evidence-based model for hand transmission during patient care and the role of improved practices. Lancet Infect Dis 6:641-652

62. Pittet D, Dharan S, Touveneau S, Sauvan V, Perneger TV (1999) Bacterial contamination of the hands of hospital staff during routine patient care. Arch Intern Med 159:821-826 
63. Quaranta D, Krans T, Espirito Santo C, Elowsky CG, Domaille DW, Chang CJ, Grass G (2010) Mechanisms of contact-mediated killing of yeast cells on dry metallic copper surfaces. Appl Environ Microbiol 77:416-426

64. Ray AJ, Hoyen CK, Das SM, Eckstein EC, Donskey CJ (2002) Undetected vancomycinresistant Enterococcus stool colonization in a Veterans Affairs Hospital using a Clostridium difficile-focused surveillance strategy. Infect Control Hosp Epidemiol 23:474-477

65. Rogers J, Dowsett AB, Dennis PJ, Lee JV, Keevil CW (1994) Influence of plumbing materials on biofilm formation and growth of Legionella pneumophila in potable water systems. Appl Environ Microbiol 60:1842-1851

66. Rogers J, Dowsett AB, Dennis PJ, Lee JV, Keevil CW (1994) Influence of temperature and plumbing material selection on biofilm formation and growth of Legionella pneumophila in a model potable water system containing complex microbial flora. Appl Environ Microbiol 60:1585-1592

67. Rutala WA, Weber DJ (1997) Uses of inorganic hypochlorite (bleach) in health-care facilities. Clin Microbiol Rev 10:597-610

68. Rutala WA, Weber DJ, HICPAC (HICPAC) (2008) Guideline for disinfection and sterilization in healthcare facilities, 2008, Healthcare Infection Control Practices Advisory Committee (HICPAC), United States of America. http://www.cdc.gov/hicpac/Disinfection_ Sterilization/acknowledg.html

69. Sala MR, Cardenosa N, Arias C, Llovet T, Recasens A, Dominguez A, Buesa J, Salleras L (2005) An outbreak of food poisoning due to a genogroup I norovirus. Epidemiol Infect 133:187-191

70. Salgado CD, Sepkowitz KA, John JF, Cantey JR, Attaway HH, Freeman KD, Sharpe PA, Michels HT, Schmidt MG (2013) Copper surfaces reduced the rate of healthcare-acquired infections in the intensive care unit. Infect Control Hosp Epidemiol 34:33382R2

71. Santo CE, Morais PV, Grass G (2010) Isolation and characterization of bacteria resistant to metallic copper surfaces. Appl Environ Microbiol 76:1341-1348

72. Sattar SA, Jacobsen H, Springthorpe VS, Cusack TM, Rubino JR (1993) Chemical disinfection to interrupt transfer of rhinovirus type 14 from environmental surfaces to hands. Appl Environ Microbiol 59:1579-1585

73. Sattar SA, Lloyd-Evans N, Springthorpe VS, Nair RC (1986) Institutional outbreaks of rotavirus diarrhoea: potential role of fomites and environmental surfaces as vehicles for virus transmission. J Hyg (Lond) 96:277-289

74. Schmidt MG, Attaway HH, Fairey SE, Steed LL, Michels HT, Salgado CD (2013) Copper continuously limits the concentration of bacteria resident on bed rails within the ICU. Infect Control Hosp Epidemiol 34:530-533

75. Schmidt MG, Attaway HH, Sharpe PA, John J Jr, Sepkowitz KA, Morgan A, Fairey SE, Singh S, Steed LL, Cantey JR, Freeman KD, Michels HT, Salgado CD (2012) Sustained reduction of microbial burden on common hospital surfaces through introduction of copper. J Clin Microbiol 50:2217-2223

76. Schmidt MG, Attaway HH, Terzieva S, Marshall A, Steed LL, Salzberg D, Hamoodi HA, Khan JA, Feigley CE, Michels HT (2012) Characterization and control of the microbial community affiliated with copper or aluminum heat exchangers of HVAC systems. Curr Microbiol 65:141-149

77. Schmidt MG, Attaway Iii HH, Fairey SE, Steed LL, Michels HT, Salgado CD (2013) Copper continuously limits the concentration of bacteria resident on bed rails within the intensive care unit. Infect Control Hosp Epidemiol 34:530-533

78. Sehulster L, Chinn RY (2003) Guidelines for environmental infection control in health-care facilities. Recommendations of CDC and the Healthcare Infection Control Practices Advisory Committee (HICPAC). MMWR Recomm Rep 52:1-42

79. Sharan R, Chhibber S, Reed RH (2011) Inactivation and sub-lethal injury of salmonella typhi, salmonella typhimurium and vibrio cholerae in copper water storage vessels. BMC Infect Dis 11:204 
80. Sharan R, Chhibber S, Reed RH (2012) Traditional copper water storage vessels and sub-lethal injury of Salmonella enterica serovar Typhi and Vibrio cholerae. J Water Health 10:271-277

81. Shaughnessy MK, Micielli RL, DePestel DD, Arndt J, Strachan CL, Welch KB, Chenoweth CE (2011) Evaluation of hospital room assignment and acquisition of Clostridium difficile infection. Infect Control Hosp Epidemiol 32:201-206

82. Simmons S, Morgan M, Hopkins T, Helsabeck K, Stachowiak J, Stibich M (2013) Impact of a multi-hospital intervention utilising screening, hand hygiene education and pulsed xenon ultraviolet (PX-UV) on the rate of hospital associated meticillin resistant Staphylococcus aureus infection. J Infect Prev 14:172-174

83. Snitkin ES, Zelazny AM, Thomas PJ, Stock F, N. C. S. P. Group, Henderson DK, Palmore TN, Segre JA (2012) Tracking a hospital outbreak of carbapenem-resistant Klebsiella pneumoniae with whole-genome sequencing. Sci Transl Med 4:48ra116

84. Souli M, Galani I, Plachouras D, Panagea T, Armaganidis A, Petrikkos G, Giamarellou H (2013) Antimicrobial activity of copper surfaces against carbapenemase-producing contemporary Gram-negative clinical isolates. J Antimicrob Chemother 68:852-857

85. Stiefel U, Cadnum JL, Eckstein BC, Guerrero DM, Tima MA, Donskey CJ (2011) Contamination of hands with methicillin-resistant Staphylococcus aureus after contact with environmental surfaces and after contact with the skin of colonized patients. Infect Control Hosp Epidemiol 32:185-187

86. Teunis PF, Moe CL, Liu P, Miller SE, Lindesmith L, Baric RS, Le Pendu J, Calderon RL (2008) Norwalk virus: how infectious is it? J Med Virol 80:1468-1476

87. United States Environmental Protection Agency (2008) EPA registers copper-containing alloy products. http://www.epa.gov/opp00001/factsheets/copper-alloy-products.htm

88. Vazquez JA, Dembry LM, Sanchez V, Vazquez MA, Sobel JD, Dmuchowski C, Zervos MJ (1998) Nosocomial Candida glabrata colonization: an epidemiologic study. J Clin Microbiol $36: 421-426$

89. Wagenvoort JH, Sluijsmans W, Penders RJ (2000) Better environmental survival of outbreak vs. sporadic MRSA isolates. J Hosp Infect 45:231-234

90. Ward RL, Bernstein DI, Knowlton DR, Sherwood JR, Young EC, Cusack TM, Rubino JR, Schiff GM (1991) Prevention of surface-to-human transmission of rotaviruses by treatment with disinfectant spray. J Clin Microbiol 29:1991-1996

91. Warnes SL, Caves V, Keevil CW (2012) Mechanism of copper surface toxicity in Escherichia coli O157:H7 and Salmonella involves immediate membrane depolarization followed by slower rate of DNA destruction which differs from that observed for Gram-positive bacteria. Environ Microbiol 14:1730-1743

92. Warnes SL, Green SM, Michels HT, Keevil CW (2010) Biocidal efficacy of copper alloys against pathogenic enterococci involves degradation of genomic and plasmid DNAs. Appl Environ Microbiol 76:5390-5401

93. Warnes SL, Highmore CJ, Keevil CW (2012) Horizontal transfer of antibiotic resistance genes on abiotic touch surfaces: implications for public health. mBio 3:e0489

94. Warnes SL, Keevil CW (2013) Inactivation of norovirus on dry copper alloy surfaces. PLoS One 8:e75017

95. Warnes SL, Keevil CW (2011) Mechanism of copper surface toxicity in vancomycinresistant enterococci following wet or dry surface contact. Appl Environ Microbiol 77:6049-6059

96. Weaver L, Michels HT, Keevil CW (2010) Potential for preventing spread of fungi in air-conditioning systems constructed using copper instead of aluminium. Lett Appl Microbiol 50:18-23

97. Weaver L, Michels HT, Keevil CW (2008) Survival of Clostridium difficile on copper and steel: futuristic options for hospital hygiene. J Hosp Infect 68:145-151

98. Weaver L, Noyce JO, Michels HT, Keevil CW (2010) Potential action of copper surfaces on meticillin-resistant Staphylococcus aureus. J Appl Microbiol 109:2200-2205 
99. Weber DJ, Rutala WA (2012) Commentary: self-disinfecting surfaces. Infect Control Hosp Epidemiol 33:10-13

100. Weber DJ, Rutala WA, Miller MB, Huslage K, Sickbert-Bennett E (2010) Role of hospital surfaces in the transmission of emerging health care-associated pathogens: norovirus, Clostridium difficile, and Acinetobacter species. Am J Infect Control 38:S25-S33

101. Weinstein RA (1991) Epidemiology and control of nosocomial infections in adult intensive care units. Am J Med 91:179S-184S

102. Wheeldon LJ, Worthington T, Lambert PA, Hilton AC, Lowden CJ, Elliott TS (2008) Antimicrobial efficacy of copper surfaces against spores and vegetative cells of Clostridium difficile: the germination theory. J Antimicrob Chemother 62:522-525

103. White LF, Dancer SJ, Robertson C, McDonald J (2008) Are hygiene standards useful in assessing infection risk? Am J Infect Control 36:381-384

104. Wilks SA, Michels H, Keevil CW (2005) The survival of Escherichia coli O157 on a range of metal surfaces. Int J Food Microbiol 105:445-454

105. Wilks SA, Michels HT, Keevil CW (2006) Survival of Listeria monocytogenes Scott A on metal surfaces: implications for cross-contamination. Int J Food Microbiol 111:93-98

106. Zimlichman E, Henderson D, Tamir O, Franz C, Song P, Yamin CK, Keohane C, Denham CR, Bates DW (2013) Health care-associated infections: a meta-analysis of costs and financial impact on the US health care system. JAMA Int Med 173:2039-2046 